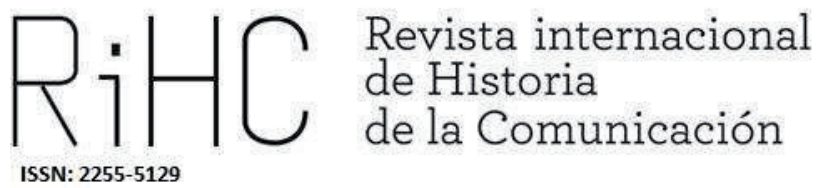

\title{
EL PAÍS DESEADO POR EL PAÍS. EL URUGUAY Y EL ENEMIGO INTERNO (1964-1973)
}

The country desired by El País. Uruguay and the internal enemy (1964-1973)

DOI: http://dx.doi.org/10.12795/RiCH.2021.i17.10

Recibido: 30-6-2021

Aceptado: 4-10-2021

Mariano Damián Montero

Investigador independiente, Universidad de Buenos Aires, Argentina marianodmontero@yahoo.com.ar

ORCID (D) 0000-0001-6555-7895 
Resumen: El objetivo del presente artículo es describir cómo uno de los principales diarios montevideanos -El País-, a mediados de la década del sesenta, se adelantó a la propia dictadura cívico-militar (1973-1985) en la utilización de un discurso represivo ligado a la Doctrina de Seguridad Nacional, que estigmatizaría a las protestas sociales como subversivas e impulsadas por intereses "foráneos". Para tal fin, se analizaron las editoriales y secciones del diario mencionado, desde el año 1964 hasta 1973.

Palabras clave: Prensa uruguaya, Doctrina de Seguridad Nacional, Dictadura cívicomilitar, años sesenta, Uruguay.

Abstract: This article analyzes the editorials and sections of one of the top Montevideo newspapers -El País-, from 1964 to 1973, to describe how this newspaper, was well ahead of their own civil-military dictatorship (1973-1985) in the use of a repressive discourse linked to the National Security Doctrine, which stigmatized social protests as subversive and driven by "foreign" interests.

Keywords: Uruguayan press, National Security Doctrine, Civil-Military dictatorship, Sixties, Uruguay.

\section{Introducción y metodología}

Hasta la década del cincuenta, el Uruguay era considerado -junto a Chile- como una de las sociedades sudamericanas más estables políticamente. Frente a las continuas tensiones políticas que se sucedían en los países vecinos de la región, Uruguay se alzaba como un ejemplo de civilidad con el funcionamiento de su sistema colegiado de gobierno ${ }^{1}$. Sin embargo, esta visión idílica que se tenía de la sociedad uruguaya, comenzó a corroerse a comienzos de la década del sesenta (Nahum y otros, 1990). Fue especialmente a partir de la asunción a la presidencia de Jorge Pacheco Areco, en diciembre de 1967, que el Estado uruguayo inició un "giro conservador" (Rico, 1989), caracterizado por medidas gubernamentales que, pese a la vigencia del estado de derecho, asemejaban al Uruguay con el resto de las dictaduras militares de la región (Argentina, Brasil, Paraguay y Bolivia). Esto se expresó en la continua aplicación de las medidas prontas de seguridad -recurso de emergencia similar al estado de sitio- a manifestaciones sindicales y estudiantiles, con el resultado de muertos como consecuencia de la represión policial. En estas circunstancias, muchos elementos que articulaban el discurso de la Doctrina de Seguridad Nacional (DSN) ${ }^{2}$ comenzaron a

1 Sistema en el que el Poder Ejecutivo era ejercido por un cuerpo denominado Consejo Nacional de Gobierno, el cual era compuesto por nueve consejeros, de los cuales seis pertenecían a la fuerza política que hubiera obtenido más votos, y los otros tres, a la siguiente. Un integrante de los nueve ejercía la presidencia del Consejo anualmente. Este sistema estuvo vigente entre 1952 y 1967, año en el que, por medio de una reforma constitucional, se volvió a un sistema presidencialista de Ejecutivo unipersonal, similar al resto de los países de la región.

2 "La Doctrina de la Seguridad Nacional (DSN) fue una ideología desde la cual Estados Unidos, después de la Segunda Guerra Mundial, consolidó su dominación sobre los países de América Latina, enfrentó la 
circular en forma masiva tanto desde el gobierno de Pacheco Areco, como desde los principales diarios de Montevideo. Palabras como foráneo, minorías, y un enfoque profundamente macartista, poblaron las editoriales y las diferentes secciones de los periódicos.

En el presente artículo nos proponemos describir e interpretar la línea editorial del diario El País entre 1964 y 1973, las ideas contenidas en la misma que comparte con los postulados de la DSN, y cómo intentó instalar estas visiones del mundo en el inconsciente de la población uruguaya. La justificación de los límites temporales del estudio se basa en que 1964 fue el año en el que Uruguay rompió relaciones diplomáticas con Cuba luego de un largo y tenso debate entre las diferentes fuerzas políticas, generando intercambios de columnas de opinión entre los diferentes periódicos con temas afines al discurso de la DSN. El límite, 1973, supuso el fin del control civil del Poder Ejecutivo y el predominio del liderazgo militar ${ }^{3}$.

Planteamos como hipótesis firme que la aplicación de los preceptos de la DSN, atribuida habitualmente a los regímenes militares de la región (Castagnola y Mieres, 1989; Buitrago, 2003; Coraza de los Santos, 2008; Peralta Barboza, 2013), fue impulsada y reclamada previamente por un determinado sector socio-económico de la sociedad civil, y que el diario El País fue el portavoz de aquel grupo. El discurso adoptado por El País en sus editoriales se anticipó a los discursos llevados a cabo por el gobierno de Pacheco Areco primero, Bordaberry después y por el régimen militar luego. Otro aspecto es que el diario mencionado mantuvo una continuidad en este sentido a nivel geopolítico por lo menos desde 1954, plasmada en sus notas sobre la caída de Arbenz en Guatemala, y que se extiende hasta el presente con su posición ante los gobiernos sudamericanos del llamado ciclo progresista (2003-2015). Por último, y en este caso a nivel discursivo, la utilización de unas pocas palabras (por ejemplo: foráneo y minoría) le permitió al matutino estigmatizar a todo colectivo político y social que intentó movilizarse por mejoras en el nivel de vida.

Como hipótesis secundarias proponemos la existencia de una colaboración entre la $\mathrm{ClA}$ (Central Intelligence Agency) y El País, fundada en los antecedentes probados por medio de documentación desclasificada de textos publicados en el periódico montevideano en 1954 con el fin de desprestigiar en la región a la figura de Jacobo Arbenz (García Ferreira, 2007).

Guerra Fría, fijó tareas específicas a las fuerzas armadas y estimuló un pensamiento político de derecha en los países de la región. Como ideología, reconoció sus orígenes en una visión bipolar del mundo desde la que, supuestamente, Occidente, liderado por los Estados Unidos, representaba el bien, la civilización, la democracia y el progreso; mientras que la entonces Unión Soviética estaba al frente del mal, el atraso y la dictadura" (Velásquez Rivera, 2004).

3 Sin embargo, trabajos como el de López Chirico, El Estado y las Fuerzas Armadas en el Uruguay del siglo XX (1985), ponen en cuestión la prescindencia política de los militares previa a 1973. 
En relación al estado de la cuestión sobre el rol de la prensa uruguaya en la coyuntura del "giro conservador" de la presidencia de Pacheco Areco, la bibliografía es escasa. No encontramos estudios específicos con respecto a nuestro objeto y período de estudio. Con respecto al análisis de la prensa uruguaya, el extenso libro-testimonio de Federico Fassano Mertens (1973) es una obra de consulta obligada como fuente directa de la época, igualmente que el de Paysse González (1968). Gabay (1988), por su parte, nos sistematiza los datos acerca de todas las clausuras sufridas por los medios de prensa entre 1967 y 1983 con los motivos correspondientes. Más cercanos en el tiempo, se pueden mencionar los libros de Álvarez Ferretjans (1986 y 2008) aunque orientados a una historia integral de la prensa uruguaya a través del tiempo con enfoques netamente formales y evadiendo la relación entre la prensa hegemónica y el poder de turno; y finalmente, más afines a nuestro enfoque, trabajos que abordan el rol de los principales diarios durante los años de la dictadura cívico-militar (1973-1985) (Albistur, 2013; Ramos, 2019), pero sin profundizar en los discursos que los precedían, asunto que sí es abordado por Von Sanden desde el humor gráfico (Von Sanden, 2015). Únicamente los trabajos de Magdalena Broquetas (2012, 2015, 2016 y 2018) abordan los aspectos que cubriremos en este texto.

Con respecto al marco teórico, tomamos como referencia el estudio de Borrat (1989) sobre el rol político del periódico, pese a que en nuestro caso no estudiamos a un diario independiente como los analizados por él, sino a uno partidario. Sin embargo, muchos aspectos de su modelo son funcionales a nuestra investigación. El Manual de periodismo (1986), de Carlos Marín y Vicente Leñero, nos proveyó una de las claves para entender desde donde habla El País. Los autores afirman que "lejos de ser un trabajo desinteresado e imparcial, el periodismo constituye una manifestación de la lucha de clases, de los intereses económicos y políticos que representa cada empresa periodística" (Marín y Peñero, 1986: 18). Asimismo, De Diego (2017) resume muy bien las diferentes corrientes teóricas que abordaron el análisis de los medios gráficos para comprender al periódico como "actor y protagonista de luchas simbólicas" (De Diego, 2017: 6). De los diferentes enfoques que describe la autora, el presente trabajo se enmarca dentro del representado por el análisis crítico del discurso, donde el discurso informativo es "concebido como parte de los discursos del poder, frente a los cuales es preciso desarrollar una crítica que devele las relaciones de dominación ocultas en el lenguaje" (De Diego, 2017: 17). A los autores mencionados, agregamos el uso de algunas categorías de análisis de Chomsky y Hermann (1990) y en el plano metodológico, el modelo de observación de las editoriales que Ricardo Sidicaro aplicó al diario La Nación de Argentina (Sidicaro, 1989).

En cuanto al estudio de la derecha uruguaya y la influencia norteamericana durante los cincuenta y sesenta, tomamos como marco referencial los trabajos de Magdalena Broquetas (2012, 2015, 2016 y 2018), especialmente su distinción entre los grupos de "derecha conservadora y autoritaria" -entre los que el presente trabajo propone ubicar 
el caso de El País-, y los "movimientos sociales y políticos antisistema" (Broquetas, 2016: 149). Acerca de las interpretaciones sobre la DSN, se tomó como modelo la descripción de Velásquez Rivera (2004).

En cuanto a la metodología del trabajo, recurrimos al análisis de los editoriales de El País siguiendo el modelo utilizado por Sidicaro (1993) en el análisis del discurso del diario argentino La Nación, para demostrar aquello de que "el editorial es la conciencia abierta de un diario, la destilación de sus esencias" (Blaustein y Zubieta, 1998: 27). Puede ser discutible si la sección editorial sea la menos leída por los lectores medios, pero es indudable que es utilizada para que los diarios se interpelen mutuamente y lo hagan también con el poder. En los editoriales, los diarios -más concretamente, sus directores o dueños, que son representantes de determinados sectores sociales- se encargan de definir cuestiones como el interés general, el bien común o el buen gobierno. Analizan el papel del Estado, su relación con la sociedad, la caracterización de los diferentes sectores sociales y la legitimidad de los actores. O sea, el país deseado. Según Sidicaro, en su estructura discursiva se dan dos condiciones: por un lado, es la expresión oficial de una publicación, y por el otro, se utilizan para interpelar a los gobiernos (Sidicaro, 1993: 9). Esta fuente principal -de la que se analizaron todas las columnas editoriales publicadas entre 1964 y 1973, además de otras secciones detalladas-, se complementó con documentos desclasificados de la Central Intelligence Agency $(\mathrm{CIA})$ y otras fuentes primarias y secundarias.

El artículo se abre con una breve descripción de la trayectoria político-ideológica de El País y a qué intereses representó. A continuación, se presentan las secciones con las que contaba el mencionado matutino y sus particularidades. Luego, se detallan las ideasfuerza instaladas por El País en sus editoriales y diversas secciones, en las que se difunden los presupuestos de la DSN en la agenda política y comunicacional del Uruguay. Éstas se acompañan con imágenes representativas de las secciones señaladas, con el fin de identificar los presupuestos mencionados. Los pasajes citados de textos publicados en El País son breves debido a una cuestión de límites a cumplir para el presente texto, por lo que aclaramos que no se trata de expresiones aisladas del matutino, sino que son muestras de un estilo altamente recurrente. Luego de un análisis de las repercusiones del caso Mitrione, al final, se establecerán algunas reflexiones abiertas a futuras investigaciones. 


\section{Resultados y discusión}

\subsection{El protagonista}

Desde 1960 hasta 1972 la tasa de difusión de los diarios en Uruguay solo fue superada en toda América por la de EEUU (OEA, 1966, 1973 y 1975). Estas cifras nos indican una realidad concreta: en el período estudiado, el periódico era un elemento del entorno cotidiano de los uruguayos. Casi 3 de cada 10 habitantes leía un diario, incluso era muy corriente que en algunas familias se leyeran dos periódicos al día (matutino y vespertino), con lo cual estamos en presencia de una sociedad informada, pero también más vulnerable a la adopción de una visión del mundo construida por otros. Respecto a esto último, oportuna es la reflexión de Sidicaro: "comprar un diario, acto ritual, es adquirir una matriz de decodificación de los hechos sociales que organiza el conocimiento sobre una realidad que al mismo tiempo construye" (Sidicaro, 1993: 7).

Dos características principales distinguen al Uruguay en este período en cuanto a su prensa escrita. La primera es que todos los periódicos surgieron y mantuvieron su condición de tribunas de los partidos políticos, y la otra, es que los directores de esos diarios eran los principales líderes de los partidos políticos o, en algunos casos, cuadros de segunda línea de los mismos ${ }^{4}$.

Compartiendo los rasgos descriptos anteriormente, El País es un matutino fundado en 1918 por un grupo de diputados pertenecientes al Partido Nacional $^{5}$, con el fin de convertirse en vocero de los opositores internos a la figura de Luis Alberto de Herrera. Su dirección pasó de generación en generación. Fue fundado por Leonel Aguirre, Washington Beltrán Barbat y Eduardo Rodríguez Larreta, y en la actualidad es dirigido por Washington Beltrán Storace, Julia Rodríguez Larreta y Martin Aguirre, nietos de aquellos. En los años sesenta, mantenía su condición de órgano de los blancos independientes, que actuaban bajo la denominación de Unión Blanca Democrática

4 En El País, Washington Beltrán Mullin, senador por el nacionalismo y director del matutino desde 1968 a 1973, anteriormente había sido presidente del Consejo Nacional de Gobierno de 1965 a 1966, para luego pasar a ser senador entre 1966 y 1973. Luego tenemos como director de Acción a Jorge Batlle Ibañez, de 1965 a 1973, años en los que siempre se presentó como candidato a presidente en el Partido Colorado por la Lista 15. Y, finalmente, quien jugó un rol protagónico en estos años: Jorge Pacheco Areco. Fue director de El Día entre 1961 y 1965 y entre 1963 y 1967 fue diputado nacional, llegando finalmente a la presidencia de la república en 1967, ejerciéndola hasta 1972 luego de asumir el cargo ante la prematura muerte del general Oscar Gestido. En cuanto a los casos de La Mañana y El Diario, publicados por la misma empresa editorial y ejemplos de dirección a cargo de segundos cuadros de los partidos, son dirigidos, el primero, por Carlos Manini Ríos, quien fuera senador por el Partido Colorado y que en estos años fue ministro del gobierno de Gestido y Pacheco Areco; y el segundo, por Eugenio Baroffio, quien fuera diputado por el mismo partido en la década del cincuenta.

5 Este grupo fundaría en 1931 el Partido Nacional Independiente (PNI), opuesto al caudillo nacional, Luis Alberto de Herrera (1873-1959). 
(UBD), anti-herrerista ${ }^{6}$. Durante los años 1964-1967 tuvo su rol oficialista con el último colegiado blanco y su rol opositor durante la presidencia de Jorge Pacheco Areco (19671972). En cuanto a su línea editorial, la misma se caracterizó por un conservadorismo liberal alineado con Estados Unidos y profundamente anticomunista.

(Des) calificado por editores de la época como "templo de la oligarquía" (Fasano Mertens, 1973: 426), y como "especialmente pro-estadounidense, liberal y partidario de la campaña anticomunista y del autoritarismo gubernamental" (Von Sanden, 2015: 70), El País se distinguió del resto por un perfil muy ligado a los sectores agroexportadores del Uruguay, a lo que también sumaba un contacto demasiado estrecho con la embajada de Estados Unidos. Fue a través de ella como los postulados de la DSN Ilegaron a EI País, quien los explotó con habilidad durante los sesenta. Las referencias son abundantes y las encontramos tanto en fuentes secundarias basadas en testimonios (Agee, 1975; Aldrighi, 2007 y 2012) ${ }^{7}$, como en documentos desclasificados de la CIA (García Ferreira, 2007), en donde se confirma claramente cómo agentes de la central de inteligencia norteamericana escribían notas y editoriales que luego eran publicadas en El País con la firma de sus periodistas. "Al leer los informes estadounidenses y los editoriales de EI País, se advierte una estrecha correspondencia entre las preocupaciones de la embajada y su inmediata repercusión en el periódico de Washington Beltrán y Daniel Rodríguez Larreta" (Aldrighi, 2007: 217).

En una fecha tan temprana como agosto de 1953, la CIA definía a El País como "a strongly anti-Communist and pro-United States newspaper"8 en un documento donde remarcaba como el matutino denunciaba a un profesor que había tenido manifestaciones anti norteamericanas frente a la ejecución del matrimonio Rosenberg. García Ferreira (2007) demostró con documentación desclasificada de la CIA cómo, en 1954, El País fue el diario uruguayo elegido por la inteligencia estadounidense para publicar sus textos que eran firmados por el periodista Diego Lujan y en los que se

6 Línea interna del Partido Nacional Independiente, fundada en 1956.

7 Agee, agente de la CIA en Uruguay entre 1964 y 1966, detalla cómo en la estación montevideana de la $\mathrm{CIA}$, había un funcionario encargado de redactar los textos que luego se enviaban a los diferentes diarios, siendo El País el favorito, donde se atacaba a la revolución cubana y a la infiltración comunista en todos los ámbitos de la vida social (Agee, 1975: 269, 280, 324, 352, 370, 379). "AVBUZZ-1 tiene acceso a toda la prensa liberal, pero utiliza con más frecuencia los dos diarios de la tendencia Unión Blanca Democrática del Partido Blanco (El País y El Plata) (...) AVBUZZ-1 le paga a los editores de los diarios sobre la base del espacio que utiliza, pero los artículos, por lo general se publican como editoriales sin firmar de los propios periódicos (Agee, 1975: 299-300).

8 CIA-RDP80-00810 A 002100680005-9, Communist reaction to the Rosenberg Execution, 24 de agosto de 1953. Disponible en https://www.cia.gov/readingroom/document/cia-rdp80-00810a002100680005-9 (consultado el 26 de mayo de 2021). Una definición similar se repite en otro documento de la CIA, de marzo de 1974: "conservative in domestic affairs, anti-Communist, pro-United States" (en "Uruguay, marzo 1974" CIA-RDP01-00707R000200100016-8, disponible en https://www.cia.gov/readingroom/docs/CIA-RDP01-00707R000200100016-8.pdf (consultado el 26 de mayo de 2021). 
denigraba a la figura de Jacobo Arbenz, recientemente derrocado en Guatemala (García Ferreira, 2007: 59 y 61).

Este antecedente nos puede ayudar a comprender mejor cómo la línea editorial de EI País tiene un hilo con el pasado y con el futuro. La categoría de "memorias discursivas" de Jean-Jacques Curtine nos provee una herramienta conceptual para entender cómo el discurso del matutino se repite una y otra vez: "Noción que remite a las formas en que un discurso hace circular en el presente (tiempo corto de la actualidad) formulaciones ya enunciadas en otros momentos históricos, generando un 'efecto de memoria'" (citado por De Diego, 2017: 22). Estas “memorias discursivas" de 1953 y 1954 reaparecerán siempre que El País advierta algún peligro. En 1964, con la campaña a favor de la ruptura de relaciones con Cuba; entre 1964 y 1973, ante la creciente movilización popular contra las medidas de ajuste, y más cerca en el tiempo, ante la posibilidad de que la antigua amenaza del Frente Amplio llegue al poder en 2005.

Hacia 1957, lideraba en ventas de ejemplares El Diario (vespertino colorado), con 148.000; seguido por El Plata (vespertino blanco), El Día (matutino colorado), y El País (matutino blanco), estos últimos oscilando entre 70.000 y 80.000 (Faraone, 1960). A principios de los años sesenta, con la desaparición de El Plata -vespertino ligado al Partido Nacional-, El País acumuló más lectores. Para 1968, El Diario seguía liderando las ventas, pero seguido muy de cerca por El País (Fasano Mertens, 1973: 88), y a partir de 1972, El País logró liderar el ranking de ejemplares vendidos con 80.000, seguido por El Diario, El Día y Ahora, posición que no abandonaría hasta el presente ${ }^{9}$. En el período estudiado (1964-1973), El País no solo alcanzó la primacía en ventas, sino que también fue el único diario que no fue censurado ni clausurado (Von Sanden, 2015: 86; Gabay, 1988) $)^{10}$.

Antes de continuar, es oportuno señalar aquí que El País representaba (y lo sigue haciendo) a una derecha "conservadora y autoritaria", pero claramente diferenciada de "otra tendencia que no se amoldaba a las democracias representativas" (Broquetas, 2016: 149). La investigadora Magdalena Broquetas establece una separación entre una derecha "demócrata" -en donde se puede incluir a El País-, caracterizada por ser "moderados en el uso de la violencia"; y otra derecha "nacionalista", cuyas acciones eran violentas y extremas (Broquetas, 2016: 162). Pese a esta diferenciación, la autora sostiene que en determinadas coyunturas, estos dos espacios de la derecha trabajaron

9 “Uruguay, marzo 1974" CIA-RDP01-00707R000200100016-8, disponible en https://www.cia.gov/readingroom/docs/CIA-RDP01-00707R000200100016-8.pdf (consultado el 26 de mayo de 2021).

10 Privilegio que le permitió consolidar su posición como el primer diario del Uruguay hasta el día de hoy, gracias a que cada clausura del resto de los diarios, aunque sea por días, le permitía captar anunciantes que aquellos perdían. La decadencia de El Día frente a El País, a raíz de una extensa clausura en 1977 es prueba de ello. 
juntos (Broquetas, 2016: 160) ${ }^{11}$. Asimismo, una diferencia fundamental, originada en el fuerte posicionamiento del diario junto a Estados Unidos, fue el antisemitismo promovido por muchos de los grupos nacionalistas, actitud enérgicamente condenada por El País ${ }^{12}$. Con respecto a esto citamos a Broquetas:

Por otra parte, el realineamiento proestadounidense de Uruguay tras la Segunda Guerra Mundial y el clima de anticomunismo propio de la Guerra Fría ambientaron, tanto en el plano objetivo como en el del imaginario, un escenario poco propicio para las ideologías vinculadas al nazifascismo y alentaron el desarrollo de posiciones conservadoras y de derecha que no supusieran cuestionamientos a la democracia liberal (Broquetas, 2012: 25).

La autora mencionada, que investiga estos temas desde hace más de diez años, asevera que a partir de 1963 estos grupos violentos comenzaron a desintegrarse, lo que motivaría la hipótesis de si fueron cooptados o integrados a la derecha "demócrata" representada por El País.

El corazón del diario era la página 5 (a veces mudaba a la página 3), en donde se encontraba su columna editorial en el margen izquierdo, la sección Se dice, el cuadro de humor gráfico, la sección de Política y Gobierno, a las que agregaban pequeños recuadros con noticias anónimas, similares a la sección Se dice, pero un poco más extensas. Se dice se utilizó para echar a rodar los rumores sin pruebas, recurso que utilizaron y utilizan muchos diarios. A todo esto, se agrega que los lunes aparecía Permanencias, una columna de opinión anónima escrita por Mario Arcos Pérez (Aldrighi, 2007: 353), en donde desde una postura ultra-católica y anti-comunista se legitimaba la desigualdad social (El País, 10-06-1974, p.5) en coincidencia con la línea del diario expresada en un editorial que justificaba la desigualdad porque "es tan antigua como el mundo" (El País, 10-08-1965, p.5). Todas las secciones eran armónicas con el mensaje del diario, incluso el chiste gráfico a cargo de José Ramón Mariño, siempre dirigido contra el sindicalismo, el Frente Amplio (FA) y cualquier asunto relacionado con posiciones identificadas con el comunismo.

\footnotetext{
11 Ejemplos de esto pueden ser los avisos publicados en El País sobre actos promovidos por estos grupos (Padres demócratas, Juventud Uruguaya de Pie (JUP), ALERTA, etc.) y el arrendamiento de los talleres gráficos del diario para que estas agrupaciones impriman sus folletos. Incluso, el 15 de julio de 1971, se publicó el editorial "El Comunismo y el embanderamiento", en donde realizan una defensa de la JUP, una organización claramente fascista.

12 Por ejemplo, el atentado contra la joven paraguaya de 17 años, Soledad Barrett, a quien le tajearon cruces esvásticas en sus muslos.
} 


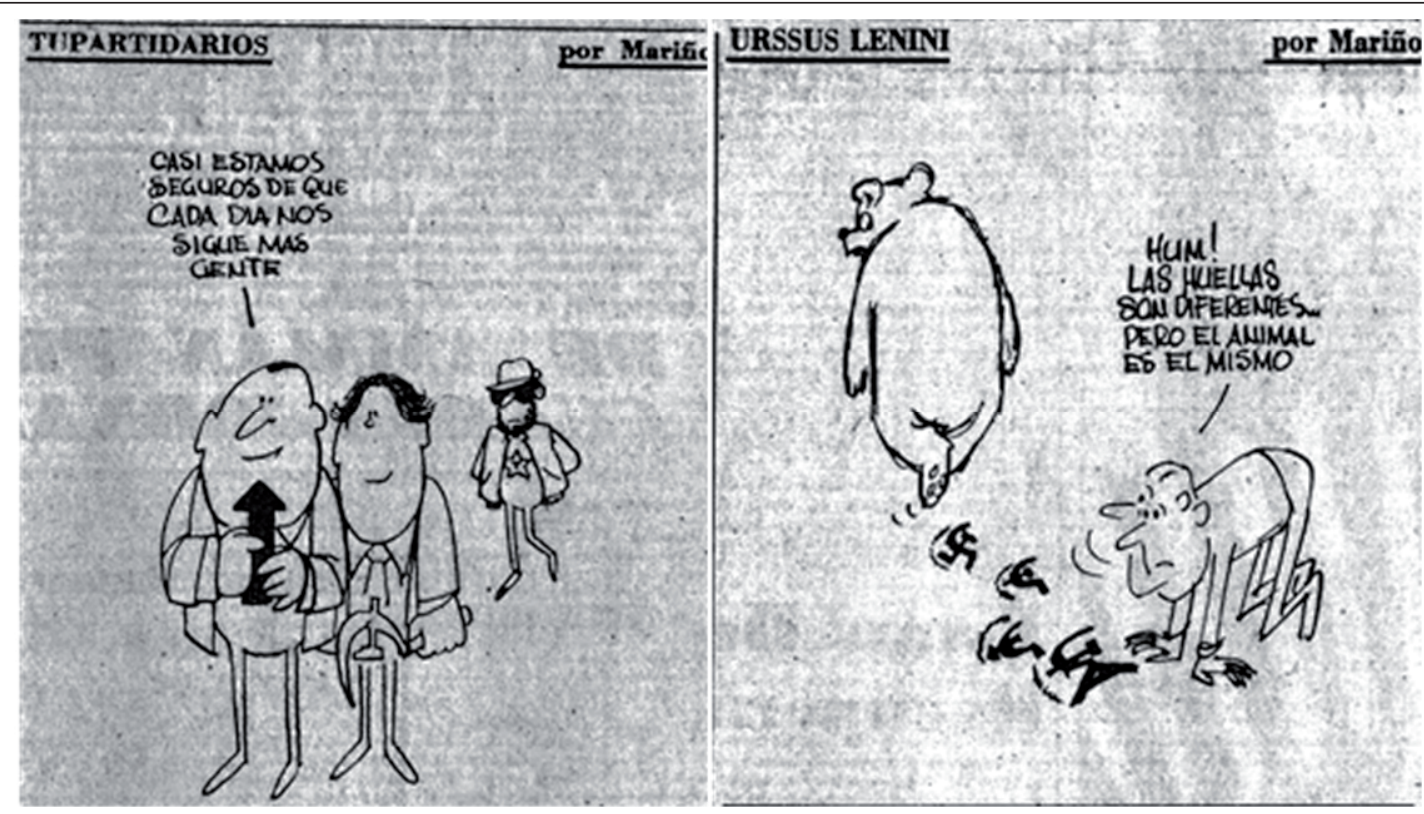

Imagen 1 y 2 . Publicados el 12 de enero de 1971 y el 14 de julio de 1971 respectivamente, parte de una campaña constante contra el Frente Amplio impulsada por El País, frente a las elecciones de noviembre de aquel año. En el primero, sugieren la asociación del FA con la guerrilla Tupamaros, y en el segundo, asocian al FA con la URSS y el nazismo.

\subsection{Ideas fuerza de El País: lo foráneo, el enemigo interno y la lógica simplificadora}

Hacia el año 1968, en el país se pasó de la propuesta liberal democrática a la liberal conservadora autoritaria, que buscó disciplinar desde arriba el comportamiento de la sociedad (Rico, 1989). El gobierno de Pacheco Areco (1967-1972) comenzó a imponer un discurso que enfrentaba tanto a la guerrilla del Movimiento de Liberación NacionalTupamaros (MLN-T) como a los sindicatos y también a buena parte de la clase política. Se comenzó a utilizar la dicotomía expresada en el binomio crisis-orden, en la que el Estado aparecía como víctima, como un tercero que venía a restaurar el orden. El discurso político del orden desplazó al discurso económico de la crisis en el que el Estado sí tenía responsabilidades ineludibles (Rico, 1989). ¿Y quiénes eran los responsables del caos? Una minoría, otro de los conceptos utilizados por El País que va unido a lo foráneo. Esta minoría que causa tantos males al país, viene de afuera o actúa por directivas que vienen del extranjero. Lo foráneo para El País es el comunismo, y éste se encuentra infiltrado, en un primer momento, en la universidad y el sindicalismo. Luego se agregarán las formaciones armadas, especialmente el MLN-T a partir de 1968. Quiere decir que lo foráneo, corporizado en la ideología comunista, contaminó a los sindicatos, a los profesores y estudiantes universitarios, y a la juventud que se plegaba a la guerrilla urbana.

A lo que viene de afuera, se le opone lo autóctono, como en el siguiente editorial en el que se justificaba la ruptura de relaciones con Cuba: "El pueblo oriental, el auténtico y 
no el de las desviadas minorías, ha oído expresada su voluntad a través del pronunciamiento del Poder Ejecutivo el martes por la noche" (Por la dignidad del país, 10-09-1964, p.5). Lo opuesto a lo foráneo es lo oriental. La orientalidad, de la que El País se convirtió en portavoz, representa lo nacional, aquello intangible que existe desde antes de 1830. Todo aquel que no apoye al gobierno es porque responde a intereses extranjeros. Ante una huelga en el Frigorífico Nacional, El País afirmó que "El F.I.de.L"13 se moviliza al servicio de Moscú tratando de engañar a las masas obreras" , reclamó "no dejarse llevar por la nariz por los comunistas extranjerizantes al servicio del imperialismo ruso" (Comunismo en el Frigonal, 16-02-1965, p.5).

Con el chivo expiatorio de lo foráneo, los motivos económicos y estructurales de las protestas sociales quedaron desdibujados y se impuso una lógica simplificadora. Ante el dilema caos-orden, el papel positivo del Estado se reforzó y, como dice Rico:

Todo ello permite estructurar una lógica simplificadora de la retórica del poder. La misma parte de la instrumentación del binomio crisis-orden, donde la sistematización del mecanismo amigo-enemigo es ese blanco-negro/bueno-malo requerido para masificar y matrizar en la conciencia de importantes sectores de la población una explicación simple para una crisis compleja, donde el discurso político del Gobierno sea, al mismo tiempo, la propaganda de la política del Gobierno (Rico, 1989: 41).

Lo foráneo (la infiltración comunista) moldea al enemigo interno, corporizado en aquellos espacios, grupos o entidades que sufrieron la infiltración de lo foráneo: los sindicatos combativos, la universidad, la juventud y sectores de la Iglesia vinculados al grupo de Medellín. ¿Cómo? A través de una lógica simplificadora ejecutada desde la mayoría de los medios de prensa cuyo ejemplo más elocuente fue el Caso Mitrione, que analizaremos más adelante bajo el esquema propuesto por Chomsky y Hermann (1990) de víctimas dignas e indignas.

Entre 1964 y 1967, la herramienta propuesta por El País para combatir al enemigo interno fue la aplicación de la ley. La demanda de judicialización del conflicto, especialmente en gremios y universidades, para que se procese a los involucrados en las protestas sociales, se vio reflejada en muchos editoriales y notas del año 1965, marcado por las movilizaciones sociales originadas en la pérdida del poder adquisitivo de las clases trabajadoras ${ }^{14}$ : "Que deben ser sancionados por la policía y la justicia las medidas violentas a las que están acudiendo activistas en huelga, si no resulta posible prevenir tales desmanes" (Sección Lo que se dice, 05-01-1965, p.5). En "Jurisprudencia sobre la

13 El Frente de Izquierda de Liberación (F.I.de.L), fue una alianza de partidos de izquierda fundada en 1962, conformada por el Partido Comunista de Uruguay y otras agrupaciones menores.

14 La necesidad de subordinar nuevamente a los sectores populares de parte de las clases dominantes en el Uruguay de los años sesenta se enmarca claramente en el modelo del Estado burocrático-autoritario de Guillermo O'Donnell (Peralta Barboza, 2013: 8). 
huelga", ofrecen argumentos para reglamentar la actividad sindical (22-01-1965, p.5). "Amnistía improcedente", en este artículo se oponen a un proyecto de Ley de amnistía para los funcionarios públicos que habían participado en la última huelga, ya que, según El País, éstas fueron sanciones administrativas y no delitos políticos, por lo tanto no correspondía la amnistía (30-10-1965, p.5). En "La clara inconstitucionalidad e ilegalidad de las conocidas huelgas de los funcionarios públicos" (24-10-1965, p.3), detallan que la Constitución no ha consagrado el derecho de huelga a favor de dichos funcionarios y que existen textos legales que sancionan el abandono colectivo del trabajo, para luego citar una serie de artículos e incisos constitucionales en los que, a criterio de El País, la huelga solo está reconocida como derecho para los privados y no para el funcionario público.

Otro de los recursos fue cultural-histórico y no legal. Ante lo foráneo, recuperar y oponer lo nacional: la orientalidad. A través de esta idea, El País logró articular un discurso de unidad nacional que podemos graficar con el siguiente pasaje:

Un vocero del extremismo local ha difundido (...) una interpretación de Paysandú que remata así "Hoy si Leandro Gómez ${ }^{15}$ pudiera levantarse, correría con su espada a sus correligionarios con el mismo ardor con que enfrentó al mitrismo y a los intrusos brasileños" (...) los orientales no tenemos ninguna duda de lo que habría hecho Leandro Gómez (...). Se rescataría a sí mismo de manos de quienes intentan apoderarse de las glorias nacionales para colgarlos del escaparate de Fidel, de Moscú, de Pekín o El Cairo y hasta es probable que se abrazaría con Flores, con Suárez y hasta con el indio Belén, y juntos todos sacarían a puntapiés -sin ensuciar sus espadas-a los que pretenden hacerles renegar de su divisa" (0401-1965, p.3)

"La opinión pública sabe que el ideario artiguista es incompatible con los principios del despotismo fidelista, ruso o pekinés" (11-04-1967, "Manoseo de Artigas", p.5). "En la hora en donde todo naufraga, lo que es seguro quede en pie es un estilo y un régimen de vida que es orgullo del Uruguay en el concierto de las naciones" (Rumores, 25-061968, p.5).

\subsection{Macartismo tardío}

Desde 1945 en adelante, la pugna ideológica entre Estados Unidos y la Unión Soviética obligó a los diferentes gobiernos latinoamericanos a alinearse junto al primero. Los grados de adhesión variaron de un país a otro, en dos niveles: gubernamental y sectorial. En el primero de ellos, dependió del elenco gobernante de turno. Así, Brasil tuvo un giro 
profundo en 1964 entre la administración de Goulart y los militares que lo derrocaron. En el caso de los grupos de poder sectoriales, éstos tuvieron una posición más estable en su adhesión a la DSN norteamericana debido a sus intereses inalterables a través del tiempo.

Una de las expresiones de este apoyo fue la difusión de lo que llamamos un macartismo tardío en la mayoría de los medios de prensa montevideanos. Prácticamente todos los grandes periódicos participaron de esta campaña anticomunista y publicaron textos que amplificaron el concepto del "enemigo interno" escondido entre la población, incitando a la delación en todos los ámbitos (Broquetas, 2015: 7). Esta práctica, en el caso de El País adquirió su mayor exposición, con la participación de funcionarios de la embajada norteamericana y de la $\mathrm{ClA}$ que intentaron orientar el perfil de los editoriales ${ }^{16}$. Como lo señalaron diferentes fuentes (Agee, 1975, Aldrighi, 2007, CIA), El País fue el principal diario que reprodujo editoriales y notas redactadas por la estación uruguaya de la CIA. No tenemos herramientas como para distinguir cuáles fueron las intervenciones redactadas por agentes de la CIA de las propias de El País, cuestión que ya abordó Clara Aldrighi, cuando afirmó que:

"La prosa estadounidense era más concisa, libre de oropeles ideológicos, invectivas y agresividad, ingredientes que abundaban en El País. El periódico difundía en ciertos editoriales una visión maniquea del mundo, manejado por fuerzas ocultas y supranacionales, al servicio del comunismo internacional, favorecidas en sus oscuros designios de dominación mundial por la categoría de 'cómplices', 'hipócritas' y 'traidores'” (Aldrighi, 2007: 217).

Sin embargo, considerar al matutino de Washington Beltrán simplemente como un receptáculo, sin autonomía alguna, de textos redactados por la CIA sería un error. Pese a la clara alineación del diario con el gobierno de los Estados Unidos, también existieron diferencias. La alianza no fue incondicional, como lo demuestra el episodio de la invasión a Santo Domingo, en el que el gobierno colegiado uruguayo presidido ese año de 1965 por Washington Beltrán, director de El País, se negó a integrar la Fuerza Interamericana de Paz (Agee, 1975: 344; Aldrighi, 2012: 94) ${ }^{17}$.

Frente a estudios que asocian este aumento de la retórica anticomunista y de la DSN con la irrupción de la guerrilla, y partiendo del Poder Ejecutivo (Franco-Iglesias, 2011: 102-103), en este trabajo sostenemos que son anteriores a la irrupción de la guerrilla y que parten de grupos económicos como El País. Las manifestaciones de esta posición se

16 El resto de los diarios también estuvieron receptivos a estas colaboraciones, como el caso de Acción durante 1964 (Aldrighi, 2012: 50).

17 Las causas expuestas por testimonios e investigaciones van desde que "la intervención unilateral constituía un precedente muy peligroso para pequeños países como Uruguay", hasta que se temía la posibilidad cierta de que Brasil invada el Uruguay legitimado en este antecedente (Aldrighi, 2012: 94 y 107). 
pueden apreciar a través de tres temas seleccionados: la ruptura de relaciones diplomáticas con Cuba (septiembre de 1964), la campaña de demonización del Frente Amplio (1971), y la denuncia de infiltración comunista en medios de prensa colegas y en la universidad.

\subsubsection{Cuba, septiembre de 1964}

La estación montevideana de la CIA tuvo como principal objetivo que el gobierno colegiado uruguayo rompa las relaciones diplomáticas con Cuba (Agee, 1975: 268). En septiembre de 1964, El País fue el principal impulsor de aquel objetivo, y durante aquellos días, luego de las manifestaciones contrarias a la ruptura, acostumbró utilizar la expresión "nazi-comunista" para referirse al gobierno cubano y a sus seguidores: "Defraudados los subversores nazi-castristas en su afán de producir víctimas durante el cerco a la Universidad" ("El comportamiento policial”, 14-09-1964, p.5), “a los turiferarios del nazi-comunismo en el Uruguay es imposible hacerles callar. Cumplen como las ranas, la consigna de chillar ininterrumpidamente" ("El Premier y un barbudo", 28-09-1964, p.5). La operación de asimilar al nazismo con el comunismo fue habitual en los artículos de El País hasta 1968, siendo uno de los últimos ejemplos "Heill Hitler Herr Castro" (03-06-1967, p.5) en donde se critica a Cuba por su "odio al estado de Israel" y su apoyo a los países árabes. Como cierre, a partir del 10 de septiembre, y por varios días, se publicaron "felicitaciones" de particulares (imposible de verificar su autenticidad) para Washington Beltrán por su voto a favor de romper relaciones con Cuba ${ }^{18}$.

\subsubsection{Campaña electoral del año 1971. Demonización del Frente Amplio}

En el ataque al FA, el macartismo se complementó con el miedo de los partidos tradicionales a la posible ruptura del bipartidismo. A diferencia de las elecciones de 1966, durante todo el año de 1971 se registró una inflación de editoriales atacando al $\mathrm{FA}^{19}$, y a la cabeza de todos, se encontraba El País. A través de una campaña sistemática de propaganda gráfica, infundió miedo en el electorado ante un posible triunfo del FA. No fueron solo editoriales. Para ese $85 \%$, que según Álvarez Ferretjans no lee los editoriales, El País se convirtió en vehículo de un verdadero terrorismo gráfico amparado en el anonimato. A continuación, solo detallaremos algunos de los avisos, todos anónimos, que se publicaron en 1971 antes de las elecciones. Cada aviso de estos se

18 Dentro del gobierno colegiado de aquel año, seis consejeros votaron por la ruptura, y tres por el mantenimiento de relaciones.

19 El Frente Amplio se constituyó en 1971 y agrupó a las fuerzas de izquierda que apoyaban el camino electoral, siendo las más representativas: el Partido Comunista de Uruguay, el Partido Socialista y el Demócrata Cristiano. 
repetía día a día y revela aquellas coyunturas de cooperación entre la derecha demócrata y la nacionalista:

- Foto de una escena en el Muro de Berlín. Levantan en alzas a un chico para que un abuelo lo vea desde el otro lado, con la siguiente leyenda: “¿Ud. quiere que sus hijos conozcan así a sus abuelos? ¿O que no lleguen a conocerlos nunca?" Firmado por ALERTA URUGUAY (superficie 50\% de la pagina, 25-11-1971, p.4).

- “El Frente Amplio gastó más de 1.000.000.000 en su propaganda ¿Quién se la paga? El exterior, el Frente Amplio pagará esa ayuda con la entrega del Uruguay al comunismo" (35\% superficie, 21-11-1971, p.14).

- “Encuesta. ¿Está Ud. seguro de cómo y por qué votará? Esta hoja lo ayudará a resolver sus dudas". A continuación, en una columna A planteaban situaciones propias de un estado de derecho (derecho a huelga, libertad de expresión, bienes personales, etc.) frente a una columna $B$, con situaciones propias de un estado dictatorial (imposibilidad de protesta, inexistencia de propiedad privada, delación de familiares, etc.); y finalizaba con "Si sus respuestas son mayoría B Ud. tiene que preguntarse ¿Qué me hizo mi patria para que quiera destruirla?" (2811-1971, p.15).

\subsubsection{Infiltración comunista}

Denuncias de infiltración comunista, que en Estados Unidos tuvieron su pico en la década del cincuenta, se reproducían en Uruguay a comienzos de los años setenta. El País denunciaba infiltración en la Universidad, en los sindicatos, en la Iglesia e incluso en los partidos políticos, en ese orden de importancia.

El macartismo tardío se manifestó en cuatro ámbitos: educativo, gremial, religioso y político. En el primero, las denuncias y delaciones se centraron en la universidad. En el artículo "Gremialismo y rectorado", se denunció a un profesor, de apellido Soriano, de "haber paseado detrás de la Cortina de Hierro" (07-10-1966, p.5). La asociación que El País realizaba de universidad y comunismo era directa: "Que la Universidad sigue desprestigiándose al adoptar en sus declaraciones un tono y estilo que parecería proceder de un comité político comunista" (11-04-1967, p.3). Refiriéndose a la "minoría comunista que controla la Universidad", escriben "consumaron este verdadero anschluss en el que no faltó ni la fuerza ni la quinta columna, como en los mejores escenarios del nazismo" (El anschluss universitario, 21-12-1966, p.5). Y desde su columna católica también hicieron su aporte a la estigmatización de la universidad: "La Universidad se ha convertido en centro de actividades políticas. La toma de la Universidad es el principio básico de la estrategia comunista para utilizar la fuerza explosiva de la juventud en su propósito de destrucción de la civilización cristiana" (Permanencias, 13-12-1966, p.5). En su ataque a la universidad pública, incluso llegaron 
a abonar la teoría de que en los edificios de la Universidad se encontraban los secuestrados por el MLN-T (“A puertas abiertas”, 09-08-1970, p.5).

En el ámbito religioso, las conclusiones de la Conferencia Episcopal Latinoamericana de Medellín (1968) y la adhesión a éstas de muchos religiosos uruguayos, hicieron que también sean señalados. Principalmente desde la columna Permanencias de tendencia ultracatólica, y sin autor que la firme, se atacaba permanentemente a religiosos progresistas.

En el ámbito político uno podía ser acusado de "simpatías comunistas" por el solo hecho de no acompañar el fervor anticomunista de El País: "La decisión del quincismo con respecto al problema de Cuba es producto exclusivo de la peligrosa y ya importante infiltración comunista que existe en el sector de la Lista 15" ("Coincidencia peligrosa", 26-09-1964, p.5). El País se dedicaba a señalar a sus colegas como posibles diarios comunistas disfrazados de demócratas: "Que El Día dedica una extensa nota informativa sobre el próximo congreso comunista" (Lo que se dice, 12-08-1965, p.5).

El rumor fue una herramienta utilizada desde siempre. El País explotó este recurso como nadie desde su sección "Se dice", conformada por cuatro o cinco sentencias anónimas sobre figuras o partidos si ningún tipo de sustento o prueba.
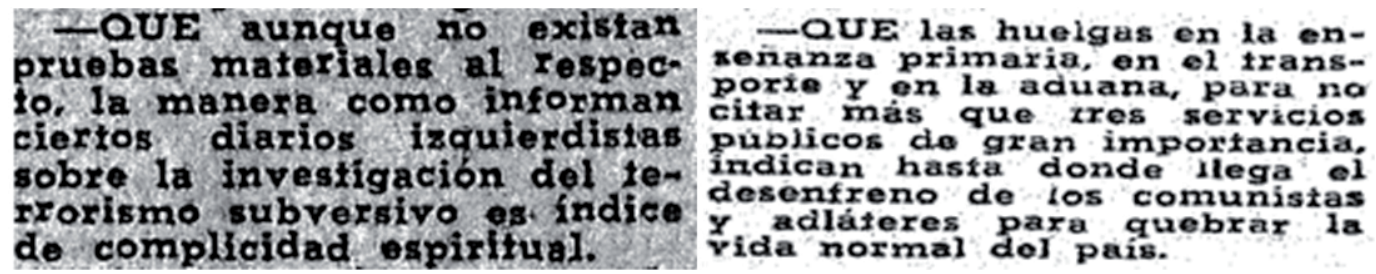

Imagen 3 y 4. Ejemplos de "Se dice" del 30-12-1966 y 4-09-1972 respectivamente.

Como muestra el primero de los recortes, la denuncia contra otros medios de prensa -a la vez competidores- de ser instrumentos del comunismo mundial, fue algo habitual en las páginas de El País. Incluso llegó al extremo de solicitar la prisión de algunos editores de aquellos medios (Fasano Mertens, 1973: 375). También podemos citar el caso del profesor y director del liceo de Florida, Salvador Fernández Correa (Broquetas, 2018: 42), quien en 1964 sufrió una campaña de desprestigio impulsada por la organización "Padres demócratas" quienes publicaban continuamente en El País. "La violencia también estuvo presente en el plano simbólico a través del fomento a las delaciones y la divulgación de información personal de los individuos y, en el plano físico, en algunas de las manifestaciones en las que participaban los movimientos demócratas" (Broquetas, 2016: 155).

Sin embargo, la mayoría de los editoriales y notas fueron dirigidos hacia el movimiento sindical uruguayo. En octubre de 1966 se unificó el movimiento obrero uruguayo en una única central obrera, la Convención Nacional de Trabajadores (CNT), lo que supuso un 
desafío para el próximo gobierno a ser elegido en noviembre de dicho año. Se buscaba un claro disciplinamiento de la fuerza laboral uruguaya, objetivo que se hizo más imperativo ante la unificación obrera de 1966. "Esta modalidad represiva adquirió regularidad en la primera mitad de la década de 1960 y se fue afianzando en simultáneo con la construcción del estereotipo del trabajador sindicalizado como "enemigo interno" y caballo de Troya del comunismo internacional" (Broquetas y Duffau, 2020: 170). Por ejemplo, ante las marchas de los cañeros, El País señalaba:

Ahora se vive otra marcha de pobres engañados y explotados por los agentes nacionales del comunismo. Lo hacen muchos de ellos cargados con sus familias, con niños, algunos de corta edad (...) como consecuencia de ello se anuncia la muerte de una criatura de pocos meses acaecida en Salto. Por lo que se ve, al comunismo no le basta con la liquidación de miles de hombres, desde Hungría al paredón cubano, para saciar su espíritu de muerte. Necesita nuevas víctimas entre los niños uruguayos (“Degradación y muerte”, 03-03-1965, p.5) 20.

Una de las particularidades de la DSN fue la de considerar a la Nación como a un ser vivo, "que debe defenderse de las agresiones externas así como de posibles enfermedades que surjan dentro de su propio cuerpo social" (Castagnola y Mieres, 1989: 85; Peralta Barboza, 2013: 13-14). Hacia 1972, los editoriales del matutino adquirieron un tono organicista y empezaron a tratar al sindicalismo como a una enfermedad, concretamente como a la meningitis, aprovechando una epidemia sufrida ese año. En el artículo "La meningitis sindical" equiparan a la actividad sindical con una enfermedad para la nación, a quien paraliza con sus huelgas. En este artículo se utilizan conceptos tales como "prepotencia sindical", "actitud antipatriótica" y "lacayos de regímenes extranjeros" (05-12-1972, p.5). Ya desde octubre de 1965, El País publicaba, uno tras otro, editoriales atacando al movimiento sindical. 


\section{LA MENINGITIS SINDICAL}

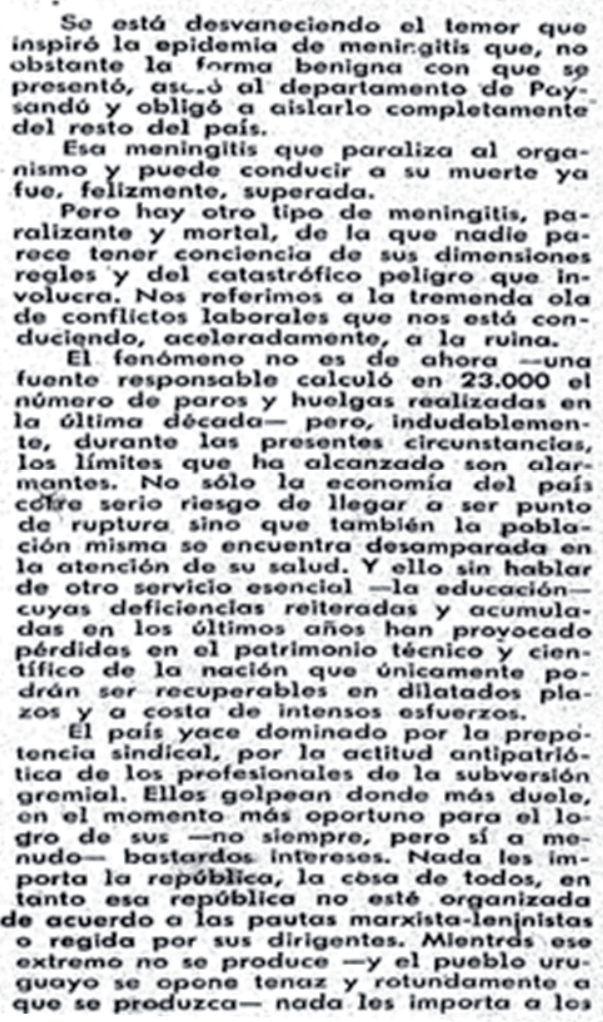

lacayos de regímenes extranjeros $y$ de Ideologias dogmaticas que los niños $y$ do la callo no eduquen, que ol hombre adecuada, quo los bareos no operen, las. fabricas no trabajen, los bancos no funcion $y$ los transportes no movilicen paasi suceda.

Ciertamente, todos tonemos nuestra cuota do responsabilidad on ol estanca miento $y$ on la rogrosion de nuestro Uruguay: los demagogos y los arribistas, los corruptos y los holgazanes, los que caresus ambicionos, los dolincuentos sodon on nómicos y los que permiten su impuno ó lucran con bl, los integranter do la subversion criminal $y$ quienes han hecho su apología y favorecido su expan sión. Pero tambión han de sentarse en el banquillo do los acusados on la medido on que sobrepasan el reclamo de una iusta remunoracion y prostituyen la lím. pida rayecto do vistas encumbradonos politicas- 1os actimuchos sindicatos que no buscan jetivo que llovar adelante ol plan a arruinar al pais, aumentando las dificultades, a fin do sembrar ol descontento favorecer, asi, la posibilidad do capta. ción de miembros para las corrientes ex-

remistas que representan.

El país dobo decidir, de una vox por todas, qub principio rector ha de prevalo. ceri si ol que pormite, como hasta ahora que grupos extranos al sentir naciónal quoongan la dirección a soguir o si el

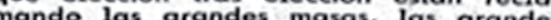
mayorís, ol autóntico puoblo or grandos principlo profundamento democratico que reconoce los derechos de todos los gru. pos pero que sostiene que por encima de ollos osta la voluntád general, libremente expresada.

\subsection{Víctimas dignas e indignas}

La aplicación de la mencionada lógica simplificadora, ejecutada desde la mayoría de los medios de prensa, tuvo su momento más álgido durante los días posteriores al secuestro y asesinato de Dan Mitrione, caso que analizamos bajo el esquema propuesto por Chomsky y Hermann (1990) de víctimas dignas e indignas. Estos autores sostienen que los medios seleccionan las noticias sobre la base de criterios valorativos determinados por aquellos que ostentan el poder. También advierten sobre la dificultad, a diferencia de los países con gobiernos dictatoriales, que implica el percibir esta situación en una democracia, donde los medios de comunicación son privados y no existe censura formal, tal el caso uruguayo.

Las llamadas víctimas dignas recibirán un tratamiento que generará el sentimiento compasivo del ciudadano, mientras que las llamadas víctimas indignas tendrán una breve alusión y un mínimo de humanidad. Tomaremos algunos casos resonantes para graficar el modelo chomskiano. Empezaremos por casos de víctimas indignas: Líber Arce, Susana Pintos y Hugo de los Santos ${ }^{21}$. A Líber Arce lo mataron el 14 de agosto de 
1968, y las reacciones en el matutino variaron desde la acentuación de lo fatal, hasta la falta de preocupación por la resolución del caso. Con respecto a los casos de Susana Pintos y Hugo de los Santos, del 20 de septiembre de 1968, hicieron focos en los daños materiales: "Pedreas y destrucciones sistemáticas, quema de autos, ómnibus convertidos en piras, las calles de Montevideo transformadas en bélicas barricadas, es algo que el uruguayo no acepta" ("Ante los acontecimientos", p.3, 22-09-1968). En los tres casos se producen las siguientes características que Chomsky/Hermann asocian con el tratamiento de las víctimas indignas: a) Omisión de detalles de las muertes. En estos casos se limitan a informar la "muerte" de los estudiantes, nada más; b) Ausencia de indignación y de demandas de justicia. Como se ve, en los párrafos citados, no existe el pedido de que se investigue; c) Ausencia de búsqueda de responsabilidad en las altas esferas. Para los diarios, el gobierno o integrantes del gobierno, no tienen ninguna responsabilidad en estos hechos, se tratan de "fatalidades".

El 17 de abril de 1972, integrantes de las Fuerzas Conjuntas -cuerpo creado por Pacheco Areco, integrado por las tres armas, Ejército, Marina y Fuerza Aérea; que, en coordinación con la policía, tuvo la misión de desarticular a la guerrilla tupamaraobligaron a salir de un local del Partido Comunista a ocho militantes y los tirotearon. Murieron siete en el acto, y el octavo, días después en el hospital por las heridas. La versión que se difundió por la prensa fue la de un "enfrentamiento". En este caso, EI País cumplió con las tres consignas anteriores. Tres días antes, el 14 de abril de 1972 el MLN había ejecutado a cuatro funcionarios del gobierno acusados de integrar el "Escuadrón de la Muerte". En respuesta, las Fuerzas Conjuntas ejecutaron a ocho militantes en diferentes redadas. Los diarios optaron por hablar de los funcionarios muertos y de cómo quedaron esas familias sin padres, omitiendo comentar cómo quedaron las familias de los ocho "sediciosos" asesinados.

En cuanto a las víctimas dignas, las características se definen por oposición a la de las víctimas indignas, o sea: a) Amplitud y repetición de los detalles del asesinato, lo que acrecienta la sensación de injusticia; b) Énfasis en la indignación y el pedido de justicia; c) El seguimiento de la noticia.

El caso por antonomasia es el de Dan Mitrione ${ }^{22}$. Durante su secuestro se publicaron continuamente en El País fotos de su familia y se insistió en su paternidad de nueve hijos. Lo secuestraron el 31 de julio de 1970 y apareció muerto el 9 de agosto de 1970. El País, el 12 de agosto, publicó un editorial titulado "Nuestra debilidad es nuestra fuerza" en donde equiparó al MLN-T con los nazis y a Uruguay con los aliados de la II Guerra Mundial que triunfaron sobre los totalitarismos manteniendo los regímenes

después. El asesinato de Líber Arce ocurrió en ocasión de las protestas estudiantiles ante la violación de la autonomía universitaria por las fuerzas policiales el 08-08-1968.

22 Dan Mitrione fue un oficial de la CIA, especialista en técnicas modernas de tortura, enviado al Uruguay para asesorar a la policía y militares (Ver Aldrighi, 2007). 
democráticos. En este caso, tenemos todas las características que identifican a una víctima digna para los medios de prensa: repetición de los detalles del asesinato, indignación por haber dejado viuda a una madre con nueve hijos y la vigencia del tema con las reproducciones de los repudios mundiales. Con los cuatro militares y funcionarios asesinados el 14 de abril de 1972 pasa exactamente lo mismo: conocemos sus historias familiares y nos indignamos porque quedan chicos huérfanos de padre, también estas son víctimas dignas.

\section{Conclusiones}

Con el presente trabajo, capítulo de uno más amplio y elaborado, creemos haber demostrado que El País adoptó entre los años 1964 y 1973 un discurso de naturaleza represiva y punitiva frente al crecimiento de las manifestaciones sociales, especialmente hacia las organizaciones sindicales. Tradicionalmente asociada con las dictaduras militares del Cono Sur como respuesta al desafío de la guerrilla, la DSN fue impulsada primero en el Uruguay por sectores civiles como el caso de El País mucho antes de la irrupción del MLN-T.

El País abrazó los presupuestos de la DSN desde sus orígenes, lo que demuestra que mantuvo una conducta coherente y sostenida por lo menos desde 1954 en adelante. Esta identificación con la DSN se vio reflejada en lo que se describió en el presente texto como un macartismo tardío, impregnado en las secciones y editoriales dirigidos contra los gremios, la universidad y políticos opositores, alcanzando su máxima expresión en las coyunturas del rompimiento de relaciones con Cuba, las elecciones de 1971 y las denuncias de infiltración comunista en diversos ámbitos de la sociedad uruguaya. Otro aspecto fue la adopción de un enfoque organicista sobre la nación, como si se tratara de un ser vivo que debía ser protegido contra enfermedades que, no casualmente, siempre venían de afuera.

Como otro aspecto del apoyo a los postulados de la DSN, sostenemos que la hipótesis de una colaboración permanente entre la CIA y El País está probada, aunque esto no significó que la agencia norteamericana haya dirigido la línea editorial del diario, sino que existió una cooperación permanente en la que ambos actores se beneficiaron, y en la que El País aceptó publicar esas intervenciones periodísticas porque coincidían con su línea editorial. Una mayor desclasificación de documentos por parte de la CIA que abarquen estos años permitirá profundizar este aspecto ya abordado por otros autores.

El espíritu del discurso de El País y sus recursos utilizados para diferenciar entre víctimas dignas e indignas, se adelantó al discurso de la dictadura cívico-militar de 1973 a 1985. Este discurso represivo, alimentado por las colaboraciones de la CIA y enmarcado en la 
DSN, desembocó en una situación no deseada por el matutino blanco: el protagonismo que adquirieron las Fuerzas Armadas, que las llevó al ejercicio directo del Poder Ejecutivo y se convirtieron en una unidad sudamericana más de la DSN. Los intereses sectoriales que El País encarnaba los acercaba a las Fuerzas Armadas, pero sus intereses políticos no, más allá de que una vez consumado el golpe militar en 1973, el diario se adaptó muy rápidamente a la nueva situación. Por lo tanto, El País claramente se ubica dentro del espectro que Broquetas categorizó como "derecha conservadora y autoritaria", pero no anti-sistema, ya que intentó mantener el estado de derecho hasta último momento y advirtió sobre los peligros de la injerencia del Ejército en la vida política.

\section{Bibliografía y fuentes}

\subsection{Periódicos}

El País (Montevideo, 1963-1974)

\subsection{Bibliografía}

Agee, P. (1975): La CIA por dentro. Diario de un espía, Buenos Aires, Sudamericana.

Albistur, G. (2013): La civilización en disputa. Democracia, institucionalidad, derechos y libertades. Dos modelos en los debates editoriales durante la dictadura uruguaya, 1973-1984, Montevideo, Universidad de la República.

Aldrighi, C. (2007): La intervención de Estados Unidos en Uruguay (1965-1973). El caso Mitrione, Montevideo, Trilce.

Aldrighi, C. (2012): Estados Unidos y Uruguay 1964-1966. La diplomacia de la Guerra Fría. Selección de Documentos del Departamento de Estado. Conversaciones reservadas entre políticos uruguayos y diplomáticos estadounidenses, Montevideo, Ediciones de la Banda Oriental.

Álvarez Ferretjans, D. (2008): Historia de la prensa en el Uruguay, desde La Estrella del Sur a Internet, Montevideo, Editorial Fin de Siglo.

Álvarez Ferretjans, D. (1986): Crónica del periodismo en el Uruguay, Montevideo, Editorial Ingenio. 
Barrios, G. (2019): "La prensa escrita como instrumento de adoctrinamiento políticolingüístico durante la dictadura uruguaya", en Marimón Llorca, Carmen y Santamaría-Pérez, Isabel (Coord.), Ideologías sobre la lengua y medios de comunicación escritos. El caso del español, Berlín, Peter Lang, pp. 35-55.

Blaustein, E. y Zubieta, M. (1998): Decíamos ayer. La prensa argentina bajo el Proceso, Buenos Aires, Colihue.

Borrat, H. (1989): “El periódico, actor del sistema político”, en Análisi, 12, pp. 76-80.

Broquetas, M. (2012): "Los frentes del anticomunismo. Las derechas en el Uruguay de los tempranos sesenta", en Contemporánea, Año 3, Vol.3, pp. 11-29.

Broquetas, M. (2015): “Una lucha sin fronteras: la derecha «demócrata» y la embestida anticomunista en Uruguay de finales de la década de 1950", en Cahiers des Amériques latines, pp. 75-96, [En linea], 79, 2016, consultado el 24 de mayo de 2021, URL : http://cal.revues.org/3644 ; DOI : 10.4000/cal.3644.

Broquetas, M. (2016): "Entre la reacción y la restauración. Derechas y violencia en Uruguay en los inicios de la crisis de la década de 1960", en Estudios IberoAmericanos, Porto Alegre, v. 42, n. 1, pp. 142-166.

Broquetas, M. (2018): "Un caso de anticomunismo civil: los "padres demócratas" de Uruguay (1955-1973)", en Páginas, año 10, no. 24 Septiembre-Diciembre, pp. 3454, consultado el 24 de mayo de 2021 en: http://revistapaginas.unr.edu.ar/index.php/RevPaginas.

Broquetas, M. y Duffau, N. (2020): “Una mirada crítica sobre el 'Uruguay excepcional’. Reflexiones para una historia de larga duración sobre la violencia estatal en el siglo XX", en Boletín del Instituto de Historia Argentina y Americana Dr. Emilio Ravignani, No.53, julio-diciembre 2020, pp.151-179.

Buitrago, F. L. (2003): “La doctrina de seguridad nacional: materialización de la guerra fría en América del Sur", en Revista de Estudios Sociales, 15, consultado el 18 mayo 2021. URL: http://journals.openedition.org/revestudsoc/26088.

Castagnola, J. L. y Mieres, P. (1989): La ideología política de la dictadura. Colección EI Uruguay de la dictadura 1973-1985, Montevideo, Ediciones de la Banda Oriental.

Coraza de los Santos, E. (2008): “Continuidades y rupturas en Uruguay: La lucha por la democracia en el último cuarto del siglo XX", en Revista Nuestra América, 6, pp. 29-62.

Chomsky, N. y Hermann, E. (1990): Los guardianes de la libertad. Desinformación y consenso en los medios de comunicación de masas, Barcelona, Crítica. 
De Diego, J. (2017): “El periódico como institución política. Claves teóricas para comprender las luchas simbólicas del discurso informativo en los grandes diarios de América Latina", en Intersticios sociales, El Colegio de Jalisco, 14, pp. 5-34.

Faraone, R. (1960): La prensa de Montevideo. Estudios sobre algunas de sus características, Montevideo, Biblioteca de publicaciones oficiales de la Facultad de Derecho y Ciencias Sociales de la Universidad de La República. Sección III-CX.

Fasano Mertens, F. (1973): Paren las rotativas, Montevideo, Editorial Octubre.

Franco, M.; Iglesias, M. (2011): "El estado de excepción en Uruguay y Argentina. Reflexiones teóricas, históricas e historiográficas", en Revista de Historia Comparada, Rio de Janeiro, 5-1, pp. 91-115.

Gabay, M. (1988): Política, información y sociedad. Represión en el Uruguay contra la libertad de información, de expresión y crítica, Montevideo, Centro Uruguay Independiente.

García Ferreira, R. (2007): La CIA y los medios en Uruguay. El caso Arbenz, Montevideo, Amuleto.

López Chirico, S. (1985): El Estado y las Fuerzas Armadas en el Uruguay del siglo XX, Montevideo, Ediciones de la Banda Oriental.

Marín, C. y Leñero, V. (1986): Manual de Periodismo, México, Grijalbo.

Nahum-Maronna-Frega-Tronchon. (1990): Historia Uruguaya, Tomo 8: El fin del Uruguay liberal, 1959-1973, Montevideo, Editorial de la Banda Oriental.

Organización de Estados Americanos. (1966): América en cifras 1965. Situación Cultural, Educación y otros aspectos, Washington, Instituto Interamericano de Estadística, Secretaría General.

- (1973): América en cifras 1972, Situación Cultural, Educación y otros aspectos, Washington, Instituto Interamericano de Estadística, Secretaría General.

- (1975): América en cifras 1974. Situación Cultural, Educación y otros aspectos, Washington, Instituto Interamericano de Estadística, Secretaría General.

Panizza, F. (1990): Uruguay: batllismo y después. Pacheco, militares y tupamaros en la crisis del Uruguay batllista, Montevideo, Ediciones de la Banda Oriental.

Paysse González, E. (1968): Editoriales de "Extra", Montevideo, Ediciones Política.

Peralta Barboza, M. (2013): Actos Institucionales de la dictadura uruguaya. Análisis de la producción legal del período (1976-1984). Monografía de grado de la 
Licenciatura en Ciencia Política, Montevideo, Instituto de Ciencia Política, Facultad de Ciencias Sociales Universidad de la República.

Real de Azúa, C. (1988): Partidos, política y poder en el Uruguay (1971: coyuntura y pronóstico), Montevideo, Departamento de Publicaciones de la Facultad de Humanidades y Ciencias.

Rico, Á. (1989): El liberalismo conservador, Montevideo, Ediciones de la Banda Oriental.

Sidicaro, R. (1993): La política mirada desde arriba. Las ideas del diario La Nación 19091989, Buenos Aires, Sudamericana.

Velásquez Rivera, É. (2004): "Historia de la Doctrina de la Seguridad Nacional", en Estudios Latinoamericanos, (14-15), pp. 74-82. Recuperado a partir de https://revistas.udenar.edu.co/index.php/rceilat/article/view/3279.

Von Sanden, C. (2015): "No fue chiste. Humor gráfico durante el período autoritario previo a la dictadura cívico-militar en Uruguay", en Revista de la Red de Intercátedras de Historia de América Latina Contemporánea, Año 2, N² 2. Córdoba, Junio -Noviembre, pp. 68-93. 